\title{
APRENDIZAJES DESDE EL HÁBITAT POPULAR: UNA EXPERIENCIA PEDAGÓGICA EN LA UNIVERSIDAD NACIONAL DE CÓRDOBA FAUD: 1991-2011
}

\author{
Aurelio Ferrero y Germán Gustavo Rebord ; con prólogo de Enrique Ortiz Flores. \\ 1a ed. Córdoba, Asociación de Vivienda Económica AVE, 2013. \\ 128 p. ISBN 978-987-27779-1-3. \\ Comentario de Arq. Rodolfo Jiménez Cavieres ${ }^{1}$
}

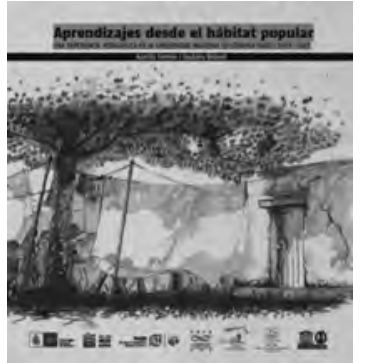

Lo que comparten los autores del libro es una práctica docente que, en forma sostenida por 22 años, ha abierto camino al tema del hábitat popular en el nivel de pre grado dentro de la Facultad de Arquitectura, Urbanismo y Diseño (FAUD) de la Universidad Nacional de Córdoba (UNC) en Argentina. Constituye un esfuerzo extraordinario por abarcar y sintetizar en 128 páginas una vastísima y rica experiencia que se ha sustentado en el trabajo de muchos profesionales y estudiantes, en especial del Arq. Aurelio Ferrero quien fue el impulsor de una cátedra específica para la formación de grado, estable, dentro de este campo.

Chile. Profesor asociado Escuela de Arquitectura Universidad de Santiago de Chile.
El libro se estructura en nueve capítulos que abarcan desde una reseña de los caminos recorridos (y sus caminantes) hasta las conclusiones. En el capítulo uno, se hace una revisión de la historia de la cátedra que ilustra la complejidad de instalar la Problemática de la Vivienda Popular en la formación de los arquitectos. Tradicionalmente las carreras de arquitectura ponen su acento o en cuestiones de orden profesional relativas al diseño, lo que descansa principalmente en los talleres, o en asignaturas tecnológicas y teóricas de la carrera desestimándose los aspectos más sociales de la carrera. 
Los impulsores de la cátedra desde su experiencia en el mundo de las ONGs, el Estado, organizaciones de base cooperativa o religiosa, reconocieron desde su práctica la dificultad para contar con profesionales motivados y formados orgánicamente para ese desempeño y emprendieron la iniciativa de instalar curricularmente estos temas en la formación de arquitectos, con una mirada holística e integrada de sus dimensiones sociales. Los autores reconocen que: "No fue sencillo, ni lo es totalmente hoy, volver a colocar en la formación superior las necesidades básicas de la población más pobre, como tema de agenda".

Se describen antecedentes curriculares de la asignatura, sus componentes pedagógicos, con ejemplos y formatos que son presentados como una referencia más, que puede ser tomada y mejorada por quienes se enfrenten a una tareas similares.

En su capítulo dos, se plantea el marco conceptual de la Problemática de la Vivienda Popular, que fundamenta y sustenta el proceso de enseñanza aprendizaje. Este capítulo es tal vez la medula del libro para los que estamos en la docencia de la arquitectura, lo que allí se recoge es la construcción teórica e ideológica que está en la base motivacional de tan larga experiencia.

Por su complejidad, el tema del hábitat popular presenta una diversidad de elementos, complejos y contradictorios, atravesados por cuestiones de índole social, política, económica, cultural, geográfica, constituyendo un universo multidimensional, cuyos componentes requieren esclarecimiento y delimitación que sin constituirse en una ideología o sistema de creencias, responde a valores y a una visión crítica de lo que sucede con la producción del hábitat humano en nuestras sociedades.

Frente a una noción de neutralidad a asepsia valórica de la docencia universitaria, la cátedra se plantea introducir "valores progresistas, solvencia técnica y capacidad de incidencia" y en ese sentido resultan muy pertinentes la preguntas que se hacen los autores respecto de ¿qué y cómo se enseña?, ¿qué conocimientos se van a comprender y practicar? Y una pregunta muy de fondo que tiene que ver con el rol de las universidades públicas: ¿deben formarse profesionales para el ejercicio liberal, o se debe apuntar a la formación de un profesional productor de conocimiento que sea un puente entre conocimientos científicos y necesidades sociales? ¿Para qué espacios de actuación institucional se quiere formar?

La Universidad pública está inmersa en una realidad y por lo tanto es necesario desarrollar procesos de formación que la articulen desde sus diversos campos de acción dándole sentido a su quehacer.

La cátedra se hace parte de la tríada universitaria docencia, extensión e investigación y concibe la educación superior como ámbito de desarrollo de la capacidad de pensamiento crítico que debe 
orientarse en pos de la acción trasformadora hacia sociedades más justas y equitativas. Para los autores, el saber científico-humanístico y saber popular-social, son necesarios para refundar la relación Universidad-Sociedad docencia, investigación y extensión universitaria, asumiendo un papel político.

Para la cátedra, la arquitectura no es sólo producción de impacto visual, está profundamente relacionada con los demás sentidos, con la historia y con la realidad contextual que construye y trasforma constantemente la esencia, el contenido y las relaciones de la disciplina. En este marco, se piensa que la complejidad del tema de la pobreza también debe ser percibida con el mismo sentido.

Desde su origen, las experiencias de investigación desarrolladas por la cátedra procuraron ligar la investigación con la acción, evitando la escisión entre la voluntad de conocer y la necesidad de hacer.

El libro recoge y muestra diez maneras de ejercitar prácticas de aprendizaje alternativas, orientadas a los estudiantes de arquitectura; las que permiten nuevas maneras de acercarse a los temas. Primero se presentan estos recursos pedagógicos a los fines de dar una idea general; finalmente se desarrolla uno de ellos.
Una cita de un estudiante grafica muy bien el sentido que se le da a la práctica en la cátedra: "desde el lugar que ocupamos como estudiantes de una universidad nacional, deberíamos tener la obligación de devolverle a nuestra comunidad algo por lo que nos fue permitido realizar nuestros estudios". Se busca una comprensión de la realidad habitacional, desde un territorio en particular, con una situación problemática real. Se procura que el estudiante elabore un diagnóstico urbano, ambiental y socio-habitacional en una comunidad específica; para ello se utilizan distintos instrumentos de enseñanza: clases teórico-conceptuales, exposiciones de profesionales invitados, salidas de campo, relevamiento técnico, entrevistas a pobladores, visitas a ONGs o municipios. Es en esta etapa donde el estudiante deberá trascender su papel de observador, asumiéndose como integrante de un equipo técnico de profesionales.

Dada la escasa atención que en general se le da al hábitat popular en la mayoría de las facultades de arquitectura de América Latina, la cátedra busca introducir propuestas pedagógicas innovativas para abordar el tema interdisciplinario del hábitat popular, las que se describen en el libro.

Significativas resultan las prácticas de la cátedra que tuvieron impacto externo y que se describen en el libro y que son las que dan sentido a su existencia y son su razón de ser. 


\section{Conclusiones}

Si bien entre el contexto universitario y el de las políticas públicas sobre vivienda popular, en Argentina y otros países, hay importantes diferencias, la experiencia expuesta en el libro, constituye una rica referencia sobre cómo abordar desde la enseñanza de la arquitectura, temas tan complejos como el del hábitat popular particularmente en condiciones de pobreza, exclusión social, desigualdad y políticas públicas deficitarias.

En Chile al igual que en argentina quienes acceden a la formación universitaria, mayoritariamente son estudiantes del amplio abanico de los sectores medios, para los cuales como dicen los autores "la pobreza constituye aquello que está detrás de un velo socialmente construido", del cual nuestras escuelas de arquitectura no están del todo excluidas.

La extendida trayectoria de la cátedra es una verdadera cantera de conocimientos que Aurelio Ferrero y Germán Gustavo Rebord y todos quienes han estado presentes en estos años generosamente comparten desde el ejercicio de la docencia en la universidad argentina intentado precisamente sacar el velo que muchas veces la academia universitaria en la enseñanza de la arquitectura extiende sobre la pobreza y el hábitat popular. Modestamente me permito recomendar la lectura de este libro, no sólo para quienes están involucrados directamente con estos temas en la docencia universitaria, sino que para los académicos y estudiantes en general. 